\title{
Influence of the sunspot cycle on the Northern Hemisphere wintertime circulation from long upper-air data sets
}

\author{
Y. Brugnara ${ }^{1,2}$, S. Brönnimann ${ }^{1,2}$, J. Luterbacher ${ }^{3}$, and E. Rozanov ${ }^{4,5}$ \\ ${ }^{1}$ Institute of Geography, University of Bern, Bern, Switzerland \\ ${ }^{2}$ Oeschger Centre for Climate Change Research, Bern, Switzerland \\ ${ }^{3}$ Department of Geography, Climatology, Climate Dynamics and Climate Change, Justus-Liebig University of Giessen, \\ Giessen, Germany \\ ${ }^{4}$ Physikalisch-Meteorologisches Observatorium Davos, World Radiation Center, Davos, Switzerland \\ ${ }^{5}$ Institute for Atmospheric and Climate Science ETH, Zurich, Switzerland
}

Correspondence to: S. Brönnimann (stefan.broennimann@giub.unibe.ch)

Received: 15 October 2012 - Published in Atmos. Chem. Phys. Discuss.: 23 November 2012

Revised: 28 May 2013 - Accepted: 29 May 2013 - Published: 3 July 2013

\begin{abstract}
Here we present a study of the $11 \mathrm{yr}$ sunspot cycle's imprint on the Northern Hemisphere atmospheric circulation, using three recently developed gridded upper-air data sets that extend back to the early twentieth century. We find a robust response of the tropospheric late-wintertime circulation to the sunspot cycle, independent from the data set. This response is particularly significant over Europe, although results show that it is not directly related to a North Atlantic Oscillation (NAO) modulation; instead, it reveals a significant connection to the more meridional Eurasian pattern (EU). The magnitude of mean seasonal temperature changes over the European land areas locally exceeds $1 \mathrm{~K}$ in the lower troposphere over a sunspot cycle.

We also analyse surface data to address the question whether the solar signal over Europe is temporally stable for a longer $250 \mathrm{yr}$ period. The results increase our confidence in the existence of an influence of the $11 \mathrm{yr}$ cycle on the European climate, but the signal is much weaker in the first half of the period compared to the second half. The last solar minimum (2005 to 2010), which was not included in our analysis, shows anomalies that are consistent with our statistical results for earlier solar minima.
\end{abstract}

\section{Introduction}

For more than two centuries scientists have been speculating on a possible influence of the solar output variability on Earth's climate and atmospheric dynamics (Gray et al., 2010 for a review; Lockwood, 2012; van Oldenborgh et al., 2013). Research in this field has progressed significantly during the last decade, mainly due to the use of global circulation models coupled with ocean dynamics and chemical processes in the stratosphere (Gray et al., 2010). In particular, a large part of the research focused on the decadal variations of total and spectral solar irradiance, namely the $11 \mathrm{yr}$ cycle. This cycle determines a change in the Total Solar Irradiance (TSI) at the top of Earth's atmosphere of about $0.1 \%$ (i.e. of the order of $1 \mathrm{~W} \mathrm{~m}^{-2}$ ), but a much larger change in the ultraviolet (UV) part of the spectrum, up to $3 \%$ according to recent measurements by the SORCE satellite (Harder et al., 2009). It also modulates the strength of galactic cosmic rays reaching Earth and geomagnetic activity. Each of these changes could have an impact on climate (e.g. Tinsley et al., 1989; Tinsley, 2000, 2012; Tinsley and Yu, 2004; Kazil et al., 2006; Meehl et al., 2008, 2009; Haigh et al., 2010; Hebert et al., 2012). However, given that the signal is weak compared to the internal variability, the relatively short period covered by observations still represents a bottleneck for a reliable quantification of this impact, especially for the troposphere. A wide spatial coverage of the atmosphere is needed, both on horizontal and vertical scale, in order to allow the validation of model 
simulations and to study the physical mechanisms involved. Until recently, the only data sets fulfilling this requisite were reanalyses that cover not more than five solar cycles, or even less if homogeneity issues are taken into account. In particular, ERA-40 (Uppala et al., 2005) and NCEP/NCAR (National Centers for Environmental Prediction/National Center for Atmospheric Research) (Kalnay et al., 1996; Kistler et al., 2001) reanalyses are widely used. Frame and Gray (2010) analysed the statistical relationships between the solar radio flux at $10.7 \mathrm{~cm}$ and zonally-averaged temperature and zonal wind in ERA-40, but they were forced to use only data from 1978 onward due to the lack of stratospheric observations in the earlier period; moreover, data after 2002 were taken from another reanalysis product. They found significant correlations in the tropical stratosphere throughout the year, while results in the troposphere were less clear. Haigh (2003) did a similar analysis for temperature in NCEP/NCAR over the period 1979-2001, finding a stronger correlation in the subtropical troposphere. Gleisner et al. (2005) tried to compare the two reanalyses over the period 1958-2001 and concluded that substantial discrepancies between the two data sets in the 1970s and the 1980s cause large differences in the correlations with the solar flux in the troposphere, particularly in the tropics and in the Southern Hemisphere; in general the correlations are much higher in NCEP/NCAR. Other inhomogeneities in the reanalyses, potentially affecting the reliability of the statistical relations with solar variability, were pointed out by other authors (e.g. Bengtsson et al., 2004; Kinter et al., 2004). One recent study (Sirocko et al., 2012) used $500 \mathrm{hPa}$ geopotential heights from the new Twentieth Century Reanalysis (Compo et al., 2011) data set, hereafter $20 \mathrm{CR}$, in addition to proxy data, finding some relationships with the solar cycle in the Euro-Atlantic region over the period 1871-2009. The statistical significance of those results was however disputed by van Oldenborgh et al. (2013).

Results from surface data, which are available for longer periods and are usually more reliable, suggest at least the existence of a solar influence. Previous studies found a significant solar influence on the wintertime sea level pressure field of the Northern Hemisphere (e.g. Kodera, 2003; Van Loon et al., 2007; Roy and Haigh, 2010, 2011; Woollings et al., 2010; Bal et al., 2011; Ineson et al., 2011; Martin-Puertas et al., 2012), although the significance of the Euro-Atlantic signal was disputed by others (e.g. Rodwell, 2003; van Oldenborgh et al., 2013). It is important to note that the signals often differ largely in strength and significance among the various studies because they are based on different data sets, periods and statistical methods. However, two common features are the weakening (strengthening) of the Aleutian low in early winter and the strengthening (weakening) of the Icelandic low in late winter during maxima (minima) of solar activity, with consequent changes in wind and temperature patterns over North America and Europe. The correlations with long data sets are generally weak and explain only a few percent of variance. Connections with surface tempera- ture are in general even weaker (e.g. van Oldenborgh et al., 2013).

Other studies focused on regions where upper-air data are reliable for long periods, typically in the mid-latitudes of the Northern Hemisphere. For instance, Brönnimann et al. (2007a) found a significant solar influence in the zonal mean of geopotential height in the upper troposphere over the period 1922-2003, when averaged over a latitudinal band spanning from $30^{\circ} \mathrm{N}$ to $60^{\circ} \mathrm{N}$. Barriopedro et al. (2008) studied the relationship between the $11 \mathrm{yr}$ solar cycle and the frequency of persistent interruptions of the normal zonal flow in the mid-latitudes, which are known as blockings (e.g. Rex, 1950). They found a significant response of the locations and persistence of blockings in the Northern Hemisphere in winter over the relatively short period 1955-1999. In particular they attributed the higher likelihood of cold days over Europe during solar minima to an eastward shift of the mean position of blockings in the North Atlantic.

The present paper aims at a more detailed and reliable description of the statistical relations between the tropospheric wintertime circulation in the Northern Hemisphere and the $11 \mathrm{yr}$ solar cycle over the last century, using state-of-theart observational data sets. Long statistical reconstructions of surface and upper-air parameters have been created in recent years, pushed by big efforts made in the recovery and digitising of old data. Furthermore, a $140 \mathrm{yr}$ long reanalysis (20CR) has been developed based on surface data only, yet demonstrating good performances for the Northern Hemisphere even in the upper troposphere for some variables (e.g. geopotential height). Our purpose is then to exploit these new data sets for a better description of the decadal variability driven by the Sun, in particular in the wintertime troposphere over North America and Europe, i.e. where the largest amount of upper-air data is available. For these regions we have the possibility to use data from the first half of the 20th century, which is fundamental to address the stability of the solar signals. Measurements of the solar radio flux are available only from the 1950s, but periods of maxima and minima of the $11 \mathrm{yr}$ cycle can still be detected from direct observations of sunspots, which are the most commonly used proxy for solar activity. In fact, the number of dark spots on the Earth-directed face of the Sun has been observed for centuries and a reconstruction is available for the last $300 \mathrm{yr}$ (for historical details refer to Eddy, 1976).

We use different, independently-developed data sets and different, complementary statistical approaches to improve the robustness of the analysis. The combination of these data sets and statistical methods provide a more reliable picture of solar induced tropospheric circulation changes than hitherto possible.

After a presentation of the data sets and the statistical methods used, we present first the results on long reconstructions of sea level pressure (SLP) for the Euro-Atlantic area, then we compare them to the results for upper-air reconstructions and reanalysis. Finally we discuss the coherency of the 
various results and describe a "solar pattern", which seems to be stable for more than $250 \mathrm{yr}$.

\section{Data}

\subsection{SLP and atmospheric circulation indices}

We use the monthly gridded SLP reconstruction for the North Atlantic-European (NAE) region $\left(30^{\circ} \mathrm{W}\right.$ to $40^{\circ} \mathrm{E} ; 30^{\circ} \mathrm{N}$ to $70^{\circ} \mathrm{N}$ ) from Luterbacher et al. (2002), which covers the period 1659-2002. The statistical reconstruction is based on a combination of early instrumental station series and documentary proxy evidence. The reader is referred to Luterbacher et al. (2002) for a detailed description of the method and the data used.

Furthermore, we consider also the monthly circulation indices reconstructed by Luterbacher et al. $(1999,2001)$ up to 1990. The indices are the North Atlantic Oscillation (NAO) and the Eurasian index (EU; Luterbacher et al., 1999); the former is the most prominent mode of variability in the Northern Hemisphere (Barnston and Livezey, 1987), and the latter also plays an important role in the variability of Eurasian climate, especially during wintertime (Schmutz and Wanner, 1998; Wibig, 1999; Xoplaki et al., 2004; Küttel et al., 2011). We analyse two versions of the NAO index and two versions of the EU index. NAO1 is calculated from gridded values of SLP, while NAO2 is from station data. EU1 (EU2) is defined as the standardised, grid point based SLP difference between Great Britain and the Black Sea (Caspian Sea). The reader is referred to Luterbacher et al. (1999) for further details on the definition of the indices.

\subsection{Upper-air data sets}

The main data sets are recently developed statistical reconstructions of global upper-air fields for temperature, wind and geopotential height: REC1 (Griesser et al., 2010) and REC2 (Brönnimann et al., 2012b). These gridded $\left(2.5^{\circ} \times 2.5^{\circ}\right)$ reconstructions are based on surface air temperature from the NASA-GISS (Goddard Institute for Space Studies) station data set (Hansen et al., 1999), SLP data from HadSLP2 (Allan and Ansell, 2006) and upper-air observations from the Comprehensive Historical Upper-Air Network (CHUAN; Stickler et al., 2010). For REC1, three different reconstructions were performed: one for the Northern Hemisphere, one for the tropics and one for the Southern Hemisphere. Here we use the first one, which covers the latitudes from $15^{\circ} \mathrm{N}$ to $90^{\circ} \mathrm{N}$. The lack of upper-air observations before the 1940s (Griesser et al., 2010) makes the tropical reconstruction unsuitable for the purposes of this paper.

Data fields are available with monthly resolution at 6 levels $(850,700,500,300,200,100 \mathrm{hPa})$, except for the wind field in REC1, which is available only for the altitude of $3 \mathrm{~km}$.

The main difference between the two data sets is related to the statistical approach. REC1 makes use of hemispheric principal component patterns, thus it is based on the assumption of stationary large-scale patterns. It has the advantage of being spatially complete with a long temporal coverage (1880-1957), but it is not suitable for detecting nonstationary teleconnections (Griesser et al., 2010). In REC2 each grid column is reconstructed independently using only predictors from a "cone of influence" around that grid column, with a minimum of $50 \%$ information from upper-air data. REC2 has the disadvantages of an incomplete spatial coverage and a shorter length (1918-1957), but the approach assures that the reconstructed values are always close to observed upper-air data.

Both reconstructions are calibrated with the ERA-40 reanalysis, from which data for the period 1958-2002 were extracted. We then chose a period in which a minimum of 500 grid points are available in REC2, with the aim to find a good compromise between temporal length and spatial coverage. The evolution of the number of available grid points is shown in Fig. 1. A grid point is considered available for a certain period when it has a maximum of 5 missing years over that period (none of them can be the first year). These criteria led to 1927-2002 (7 solar cycles) as base period of the analysis. Most of the available grid points are over landmasses in the mid-latitudes of the Northern Hemisphere, covering a large part of North America and Europe; in addition, a few grid points are available in the Caribbean Sea (see Fig. 5).

Furthermore, we compare the statistical reconstructions with 20CR (Compo et al., 2011). This reanalysis is based on sea-surface temperatures (SST) and SLP observations only, which means that it is almost independent from both REC1 and REC2 (SLP being the only common input, although with a different temporal resolution).

20CR is not affected by some common inhomogeneities of reanalysis products, such as the ones caused by the introduction of satellite-based measurements of upper-air temperature at the end of the 1970s. For this reason it represents an appropriate tool to evaluate the reliability of our analysis, which over the period after 1957 is influenced for both statistical reconstructions by the inhomogeneities of ERA-40. However, 20CR is based on version 2 of the Hadley Centre SST data set (HadSST2; Rayner et al., 2006), which has been shown to have a large inhomogeneity in the mid-1940s due to uncorrected instrumental biases in the ship-based measurements of water temperature (Thompson et al., 2008). The impact of this inhomogeneity on the upper-air fields of 20CR has not yet been evaluated in the published literature. The variations in the number of surface stations may also cause inhomogeneities; moreover 20CR suffers from a large, timevarying bias in the temperature and wind in the Arctic (e.g. Brönnimann et al., 2012a). Another weakness is represented by the fact that land-based surface pressure stations are calibrated on the ship-based observations, introducing spurious low-frequency variability. 


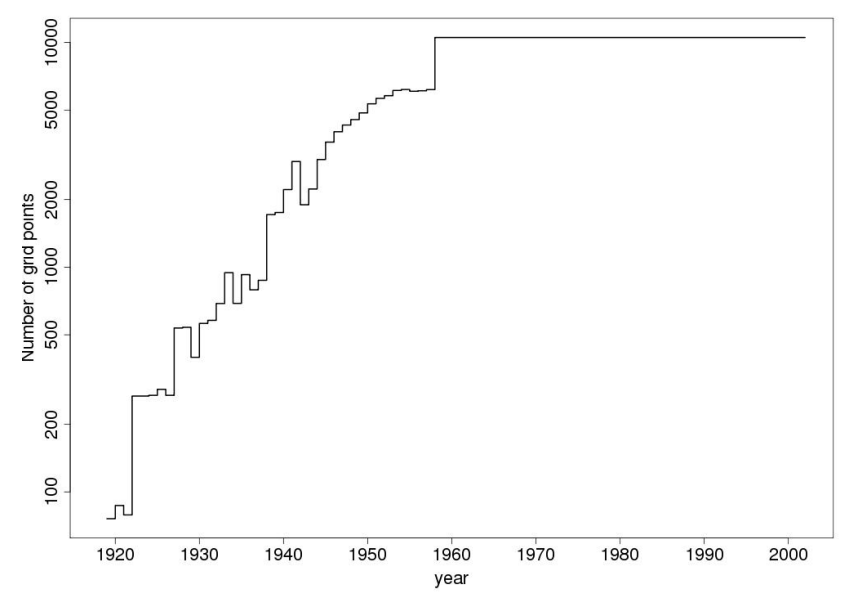

Fig. 1. Evolution of the number of available grid points in REC2 for late winter (JFM). Note that the scale is logarithmic.

\section{Methods}

We concentrate on the late-winter season (January to March, or JFM), when solar influence is expected to be at its peak in the troposphere. In fact, several studies suggested a propagation of the solar signal from the stratosphere to the troposphere during the winter season (e.g. Shindell et al., 1999; Ineson et al., 2011), hence a signal in the troposphere is expected to appear only in late winter.

Years with strong El Niño/La Niña (hereafter ENSO) episodes (as listed in Brönnimann et al., 2007b) or influenced by major volcanic eruptions are excluded from the analysis (we defined a winter to be volcanic when the average stratospheric optical depth of the Northern Hemisphere (30$90^{\circ} \mathrm{N}$ ) from the reconstruction of Crowley et al. (2008) is greater than 0.05 in JFM minus 6 months, i.e. in the period from July to September of the previous year). The reason is the non-negligible influence of strong volcanic or ENSO episodes on the wintertime extra-tropical circulation (e.g. Moron and Plaut, 2003; Brönnimann et al., 2007b; Fischer et al., 2008; Graf and Zanchettin, 2012; Zanchettin et al., $2013 \mathrm{a}, \mathrm{b})$. Twenty-five volcanic winters, starting from the year 1749, were excluded according to our criteria; fourteen of them are in the nineteenth century, six of which are in the 1810 s. We can therefore exclude a large volcanic or ENSO bias in our results.

We use two different statistical methods: the difference of composites and the multiple linear regression (MLR). The former method is applied to detect the influence of the $11 \mathrm{yr}$ cycle by checking for statistically significant differences between the mean fields during solar maxima and solar minima. This strategy is particularly useful when a strong nonlinearity of the studied connection is expected, as is the case for solar influence.

To discriminate between solar maxima and minima, we considered the upper (for maxima) and lower (for min-

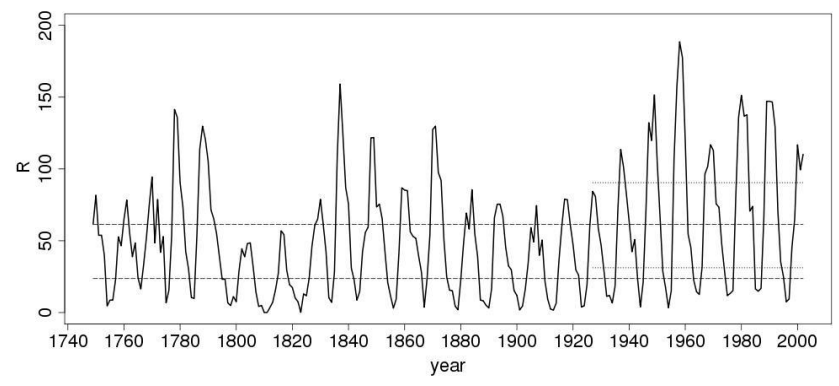

Fig. 2. Evolution of the seasonally-averaged International Sunspot Number $(R)$ in late winter (JFM) over the analysed period (17492002). The dashed (dotted) lines mark the thresholds used to define the composites for the surface (upper-air) analysis.

ima) terciles of the seasonal mean of the International Sunspot Number record ( $R=10 N+n$, where $N$ is the number of sunspot groups on the visible solar disk and $n$ is the number of individual sunspots), downloaded from the Royal Observatory of Belgium's website (http://sidc.oma. be/sunspot-data/SIDCpub.php). Application of this approach for periods of steady increase of the solar activity (e.g. 1900-1950) is not straightforward. Some reconstructions (e.g. Shapiro et al., 2011) show a long-term TSI trend which could lead to the fact that TSI for sunspot maximum around 1900 could be comparable or even lower than TSI for sunspot minimum around 1945. However, some other studies (e.g. Schrijver et al., 2011) conclude that the long-term trend of the TSI does not exist, which justifies the application of $R$ as a proxy for creating our composites. The sunspot number, plotted in Fig. 2, is available with a monthly resolution starting from the year 1749; therefore we analyse the solar signal at the surface in the period 1749-2002 (1749-1990 for the circulation indices), which covers 23 solar cycles. This is also the period when the surface reconstructions are more reliable (Luterbacher et al., 1999, 2001, 2002).

For the surface analysis we estimated the terciles of $R$ from the whole period 1749-2002, and for the upper-air analysis from the period 1927-2002 (because of the higher solar variability in that period); the thresholds are shown in Fig. 2. Other ways to define the composites, like using different thresholds for each cycle, did not remarkably influence our results. Furthermore, we tried to use the open solar flux (Lockwood et al., 2010; Woollings et al., 2010) as a proxy instead of $R$, but also in this case the results were not substantially modified (not shown).

The significance of the difference for each grid point was calculated from a standard Student's $t$ test. Field significance was estimated by adapting the method proposed by Livezey and Chen (1983). We ran a Monte Carlo simulation that consisted in replacing the years in the two composites with random years and calculating the number of grid points $m$ with a significant difference (at $5 \%$ level) for the random composites. The process was repeated 1000 times, leading to 
the null-distribution of $m$. The 95th percentile of the nulldistribution represents our significance threshold $m_{95}$ (i.e. the minimum $m$ to be achieved in order to have a significant solar influence).

MLR can better separate the influence of solar activity from the influence of other known factors (e.g. ENSO, volcanoes), assuming that each predictor has a linear relationship with the predictand. The predictors used in the MLR are $R$ representing solar activity, the Nino3.4 index (Rayner et al., 2003) representing ENSO, the Northern Hemisphere average of the stratospheric optical depth (Crowley et al., 2008) representing volcanic activity, the smoothed (10 yr running average) Atlantic Multi-decadal Oscillation Index (Enfield et al., 2001) representing oceanic low-frequency variability, and a linear trend. We applied a lead of 4 months to the ENSO predictor and a lead of 6 months to the volcanic predictor (e.g. Brönnimann et al., 2007a; Lean and Rind, 2008) in order to allow the propagation of the signals to high latitudes (the choice of the lead does not remarkably affect the results; not shown). Note that the volcanic/ENSO filter was not applied in the MLR analysis. The equation that describes our least squares regression model has the following form:

$$
\begin{aligned}
& y(\lambda, \varphi, t)=c_{0}+c_{t}(\lambda, \varphi) \cdot t+c_{R}(\lambda, \varphi) \cdot R(t) \\
& \quad+c_{\mathrm{ENSO}}(\lambda, \varphi) \cdot \operatorname{Nino} 3.4(t)+c_{\mathrm{VOLC}}(\lambda, \varphi) \cdot \operatorname{sod}(t) \\
& \quad+c_{\mathrm{AMO}}(\lambda, \varphi) \cdot \operatorname{AMO}(t)+\operatorname{res}(\lambda, \varphi, t),
\end{aligned}
$$

where $\lambda$ is longitude, $\phi$ is latitude, $t$ is time in years and res represents the residuals, i.e. the differences between observed and modelled data.

For the estimation of the uncertainty in the regression coefficients we took into account the autocorrelation of the residuals, adopting the same method as described in Garny et al. (2007).

Since we are mainly interested in the decadal signal, the difference of composites is the primary method adopted in this paper, while we use the MLR to show that the choice of the method does not significantly influence the final results (in particular, that the global warming trend is not antialiased into the solar cycle signal).

\section{Solar signal at the surface}

\subsection{SLP field}

The difference of solar maxima and minima composites for the late wintertime shows a negative solar signal in a wide area between Iceland and the British Islands (corresponding to 28 grid points, which is statistically significant since $m_{95}=24$ ), where the pressure is more than $2 \mathrm{hPa}$ lower in the solar maxima subset, indicating a strengthening of the Icelandic low (Fig. 3a). This result is in qualitative agreement with previous studies based on shorter data sets (Roy and Haigh, 2010; Woollings et al., 2010; Ineson et al., 2011); however our results indicate a more significant signal in the
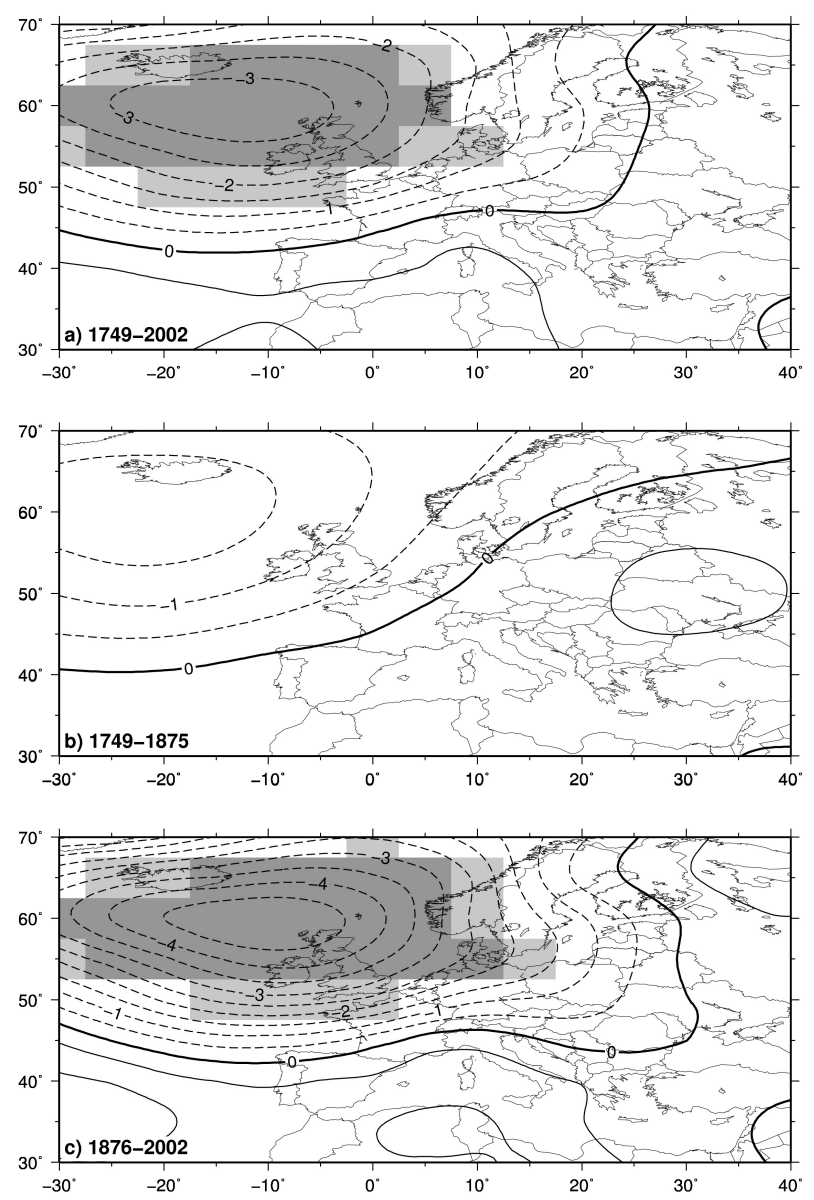

Fig. 3. Maps of differences between maxima and minima composites for the SLP reconstruction by Luterbacher et al. (2002) over (a) the whole analysed period, (b) and (c) the first and the second half of the whole period respectively. Light (dark) gray shaded areas indicate significant differences at the 5\% (1\%) level after a Student's $t$ test; units are hPa.

North Atlantic and a less strong response over north-western Africa. Differences in the results might be also due to a different definition of the winter season and the use of different data sets.

In order to assess the stability and the robustness of the signal, we repeated the analysis using two sub-series of the SLP record spanning the first and the second half of the whole period (1749-1875 and 1876-2002, respectively). The respective composites differences are shown in Fig. $3 b$ and c. The solar signal maintains its shape in the two sub-periods, although in the first period it is not statistically significant.

By looking separately at each single month (see Fig. S1 in the Supplement), we found that the signal is stable from January to March and it subsequently disappears in April, confirming that the choice of JFM for the analysis was justified. 
Table 1. Differences between solar maximum and minimum composites for various atmospheric indices in JFM over the period 1749-1990, together with their $99 \%$ confidence intervals. Values in bold are significantly different from zero at $5 \%$ level after a twosided Student's $t$ test for the differences (note that none of the indices is subject to a significant serial correlation when using JFM averages). Refer to the text for details about the filtering procedure.

\begin{tabular}{lrr}
\hline & Filtered & Unfiltered \\
\hline NAO1 & $0.38 \pm 0.54$ & $0.26 \pm 0.43$ \\
NAO2 & $0.34 \pm 0.58$ & $0.23 \pm 0.46$ \\
\hline EU1 & $-\mathbf{0 . 3 8} \pm \mathbf{0 . 3 0}$ & $-\mathbf{0 . 2 1} \pm \mathbf{0 . 2 4}$ \\
EU2 & $\mathbf{- 0 . 4 2} \pm \mathbf{0 . 3 9}$ & $-\mathbf{0 . 2 9} \pm \mathbf{0 . 3 1}$ \\
\hline
\end{tabular}

\subsection{NAO indices}

The solar signal in the SLP and geopotential height fields over the NAE region has been often interpreted as a solar modulation of the NAO (e.g. Shindell et al., 2001; Boberg and Lundstedt, 2002, 2003; Kodera, 2003; Thejll et al., 2003; Woollings et al., 2010; Ineson et al., 2011). The differences between the maximum and minimum composites for the two versions of the NAO index for JFM over the period 17491990 are summarised in Table 1. Volcanic and ENSO years were excluded from the calculation adopting the same criteria used before, but we also provide the results for the unfiltered data sets for comparison. The NAO index is slightly higher (i.e. more positive) during solar maxima, but the difference does not reach the significance level of $5 \%$ after a standard two-sided Student's $t$ test (see also van Oldenborgh et al., 2013).

\subsection{EU indices}

Table 1 shows also the composite differences for the two EU indices. Contrary to NAO's case, we found a significant solar influence for both EU1 and EU2, even when volcanic and ENSO years were not filtered out (however the significance of the differences decreased when these "disturbed" years were not removed). A scatter plot of EU1 against $R$ is shown in Fig. 4; interestingly enough, during solar minima the EU1 index had strongly negative values only for volcanic or ENSO years.

\section{Solar signal in the upper-air data}

\subsection{Geopotential height}

A significant solar influence on the boreal extra-tropical geopotential height can be detected at all tropospheric levels. In Fig. 5 we show the composites difference for $300 \mathrm{hPa}$ geopotential heights in the three considered data sets for the period 1927-2002. Figure 6 presents the same, but using

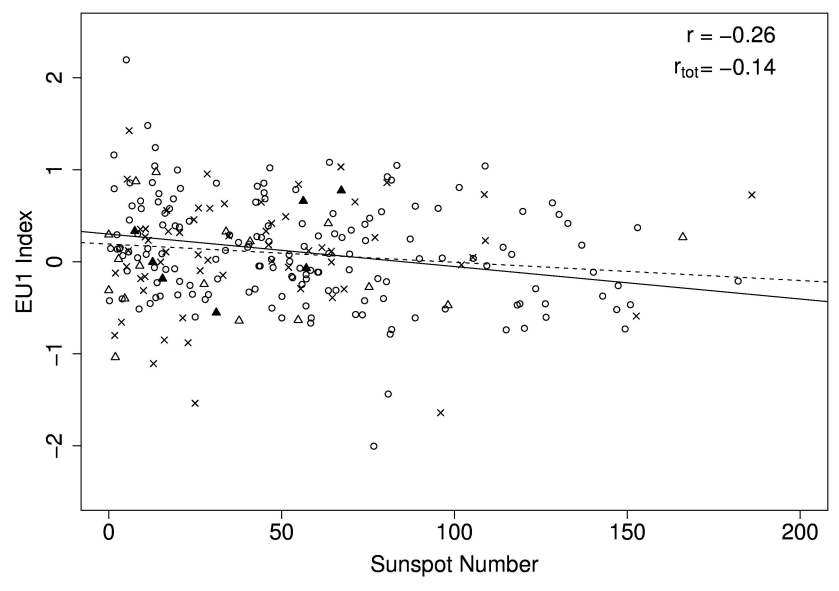

Fig. 4. Scatter plot of the sunspot number versus the EU1 index reconstructed by Luterbacher et al. (1999); both are seasonal (JFM) mean over the period 1749-1990. Triangles represent volcanic years, while crosses represent ENSO years; filled triangles are both volcanic and ENSO years. The dashed line is the least squares regression line considering every data point, while the continuous line is for "neutral" years only (no volcanic and no ENSO years); the respective Pearson's coefficients $r_{\text {tot }}$ and $r$ are also shown.

the MLR. Results are very similar for the lower levels (not shown).

The three data sets agree quite well on the pattern of the solar signal in the upper troposphere, which appears as a tripole with negative centres over Iceland and north-eastern Africa and a wide positive centre stretching from western Mediterranean to eastern Europe following a southwest-to-northeast axis. Another spot of significant negative differences is detectable over the west coast of North America. 20CR shows slightly stronger signals in the mid-latitudes, while the statistical reconstructions reveal a much stronger solar influence in the tropics. For the latter discrepancy we believe that the reconstructions are more reliable since they are based on real upper-air data; moreover the quality of 20CR is much lower in the tropics than in the mid-latitudes (Compo et al., 2011).

The MLR gives almost identical results at high latitudes, while in the tropics some remarkable differences in the significance of the signal are prevalent in the Gulf of Mexico (for REC2). Note that the values of the solar coefficient in Fig. 6 are scaled to represent a change of 100 units of the sunspot number and that they are not directly comparable to the composites differences.

In general, the discrepancies in the solar signal that arise from the use of different data sets and different methods reduce our confidence in the results for tropical latitudes.

\subsection{Wind}

The changes in the geopotential field imply changes in the atmospheric circulation, which can be observed in Fig. 7 and in Fig. 8 for the $u$ and $v$ component of the $300 \mathrm{hPa}$ wind 

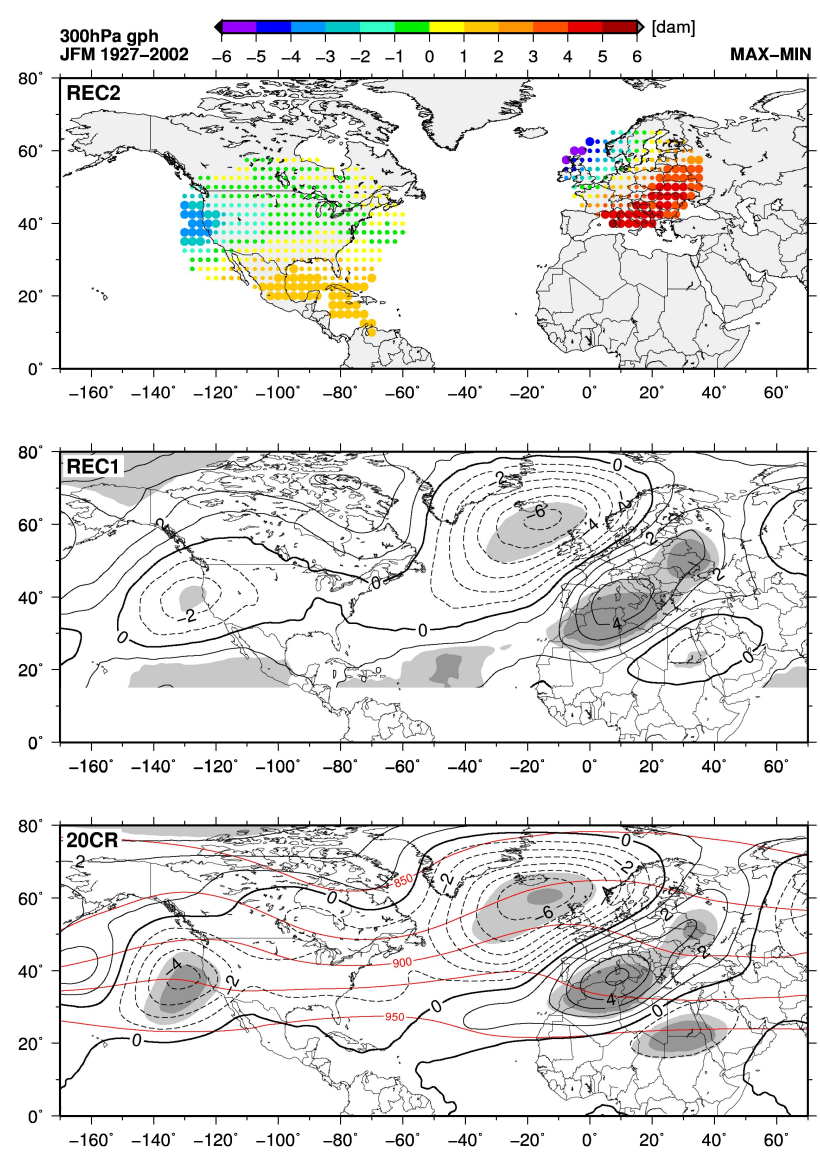

Fig. 5. Maps of differences between maxima and minima composites for $300 \mathrm{hPa}$ geopotential height in the REC2 reconstruction (top panel; big circles represent significant differences at $5 \%$ level after a Student's $t$ test), the REC1 reconstruction (middle panel) and the 20CR (bottom panel). Shadings are as explained in Fig. 3; red lines in the bottom panel represent the geopotential height climatology over the period 1927-2002. Units are dam.

respectively. Note that these variables are not available in REC1, therefore only REC2 and 20CR are shown.

The zonal flow is particularly affected at sub-tropical latitudes, where we find a clear weakening of the sub-tropical jet over northern Africa during solar maxima. An important caveat for this claim is that we can rely only on $20 \mathrm{CR}$ as REC2 does not cover the area of interest.

At solar maximum the zonal flow is enhanced over the southern part of the United States. In this case the two data sets do not agree very well; the signal is stronger and wider in REC2. The agreement is better for western Europe, where another significant signal is found. 20CR also indicates a reduction of the wind speed between Iceland and Greenland, and another smaller weakening is detectable over southwestern Canada, suggesting a southward shift of the polar jet.
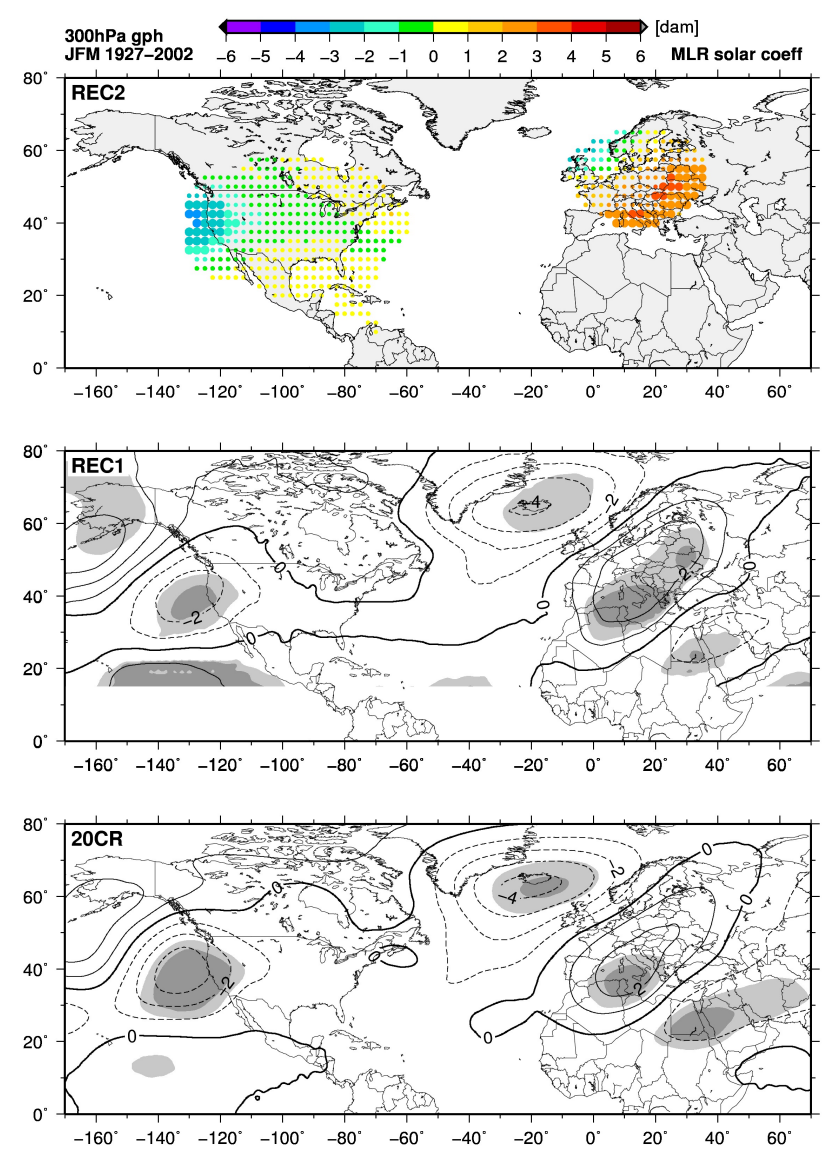

Fig. 6. Same as Fig. 5, but showing the solar coefficient $c_{R}$ (in $\mathrm{dam} / 100$ units of $R$ ) of a multiple linear regression instead of the composites difference.

A strong solar influence (up to $21 \%$ of explained variance when considering the filtered data set) is present for the meridional component over northern and western Europe (Fig. 8). The significantly higher $v$ during maxima actually represents a weaker meridional circulation, because in that area $v$ is climatologically negative (i.e. southward). Figure 9 helps in the interpretation of this feature, showing how the wind field over Europe appears according to the phase of the solar cycle. During minima the air flow is substantially recurved to the south and north-westerlies dominate over much of central Europe. This can be seen as a larger amplitude of the stationary planetary wave which characterises European climate (see e.g. Peixoto and Oort, 1992). The latter assertion is also supported by the last panel of Fig. 5, where the climatology (1927-2002) of the geopotential height in 20CR is shown; the wave-like structure over the mid-latitudes is clearly visible, in particular the ridge over north-western Europe is overlapped by a negative solar signal (i.e. a weakening of the stationary wave during solar maxima).

In contrast with the results for the other variables, the solar signal does not reach the field significance threshold in 

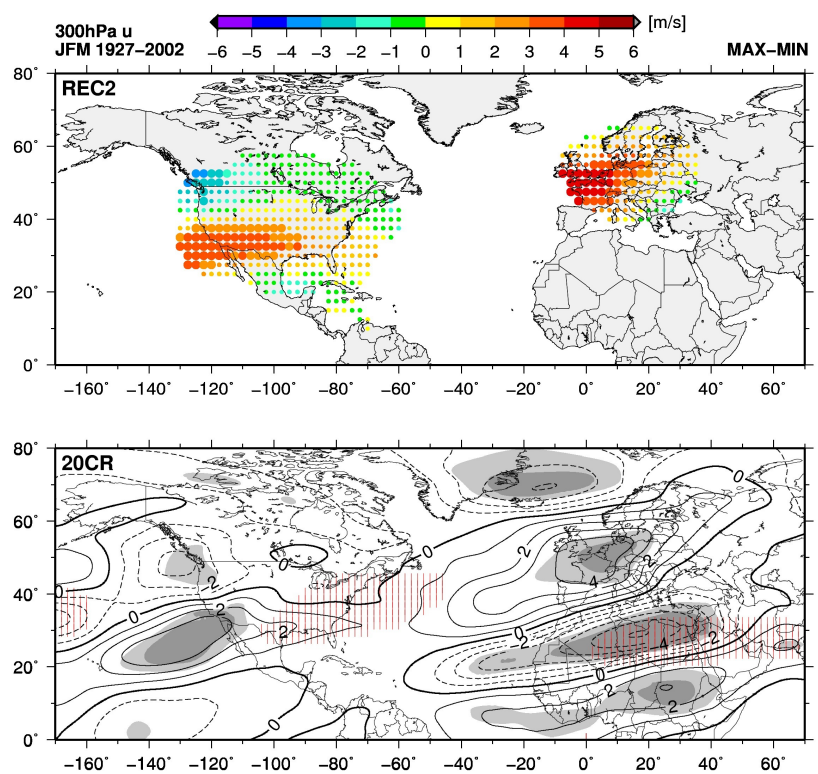

Fig. 7. Similar to Fig. 5, but showing zonal wind in $\mathrm{m} \mathrm{s}^{-1}$. Red lines localise the strongest sections of the jet stream $\left(\geq 30 \mathrm{~m} \mathrm{~s}^{-1}\right)$ in the 1927-2002 climatology for 20CR.
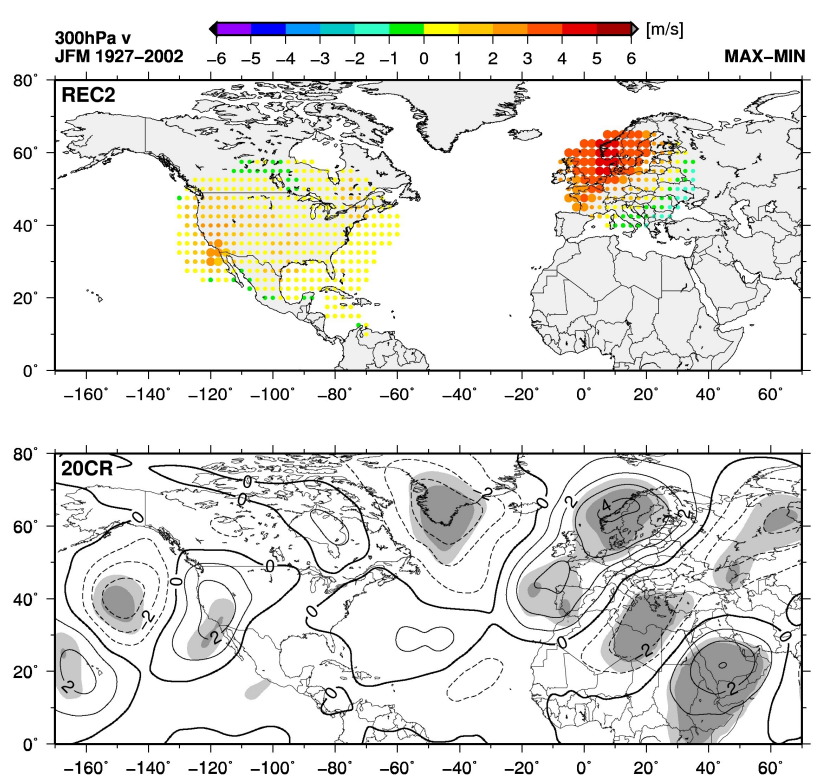

Fig. 8. Similar to Fig. 5, but showing meridional wind in $\mathrm{ms}^{-1}$.

REC2 for $v$ when considering all the grid points (it is however significant when considering Europe only). 20CR suggests a wave-like pattern of influence with most of the centres of action (Greenland, eastern Mediterranean, eastern Africa) outside of the area covered by REC2. Over North America the meridional wind is not significantly affected, although a larger solar influence is present over the north-eastern Pacific Ocean in 20CR.

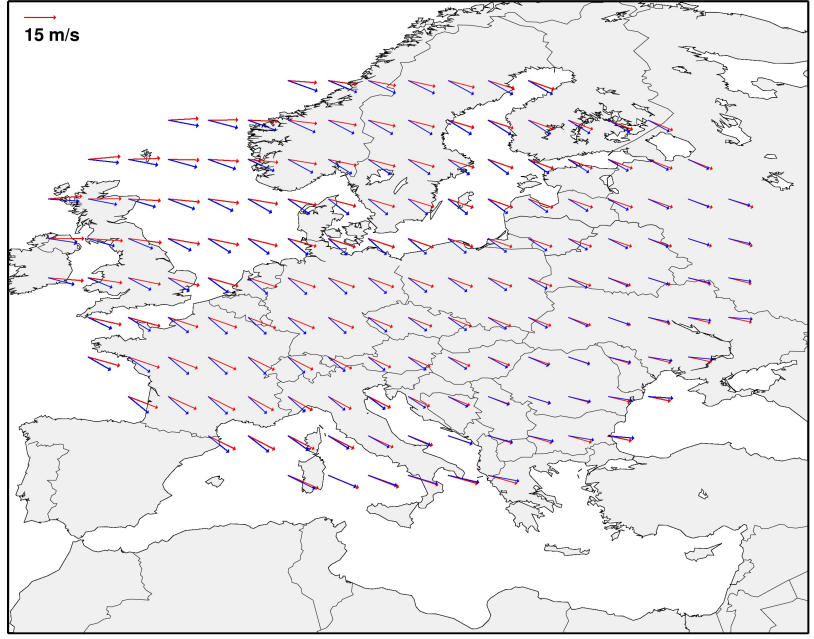

Fig. 9. Wind vectors representing average conditions at $300 \mathrm{hPa}$ in JFM during solar maxima (red arrows) and solar minima (blue arrows) over Europe. The length of the arrows is linearly proportional to the wind speed. Data are from REC2 (1927-2002).

For REC1, only the wind field at an altitude of $3 \mathrm{~km}$ is available. For the sake of completeness, we analysed this field too by comparing it with $700 \mathrm{hPa}$ wind from the other two data sets (after 1957 the $3 \mathrm{~km}$ wind field has been linearly interpolated from ERA-40). The results are shown in Fig. S2 and $\mathrm{S} 3$ in the Supplement for $u$ and $v$ component, respectively. The agreement between the data sets is very good; the patterns in 20CR are also found in REC1. Another interesting result is the small dependence of the solar fingerprint on the choice of the level, at least in the troposphere (see Figs. 7 and 8 for comparison).

\subsection{Temperature}

Figure 10 shows the composites difference for the temperature field at $300 \mathrm{hPa}$. Not surprisingly, the disagreement between the reconstructions and the reanalysis is more pronounced than for geopotential height or wind. The temperature field is not expected to be very reliable in $20 \mathrm{CR}$, but also in the reconstructions its estimated uncertainty is high if compared to the other variables (Griesser et al., 2010; Brönnimann et al., 2012b). Moreover, temperature in the upper troposphere is affected by inhomogeneities in ERA-40 (Gleisner et al., 2005).

The analyses for REC1 and REC2 exhibit a large area of positive temperature difference which goes from the tropical Pacific to southern Europe. 20CR, on the other hand, shows a significant negative difference over North America and the North Atlantic. In both cases there is a higher meridional gradient during solar maxima, which is physically consistent with the stronger zonal winds that we observe in Fig. 7.

Even more remarkable is the impact in the lower troposphere. Here we observe a strong amplification of the solar 

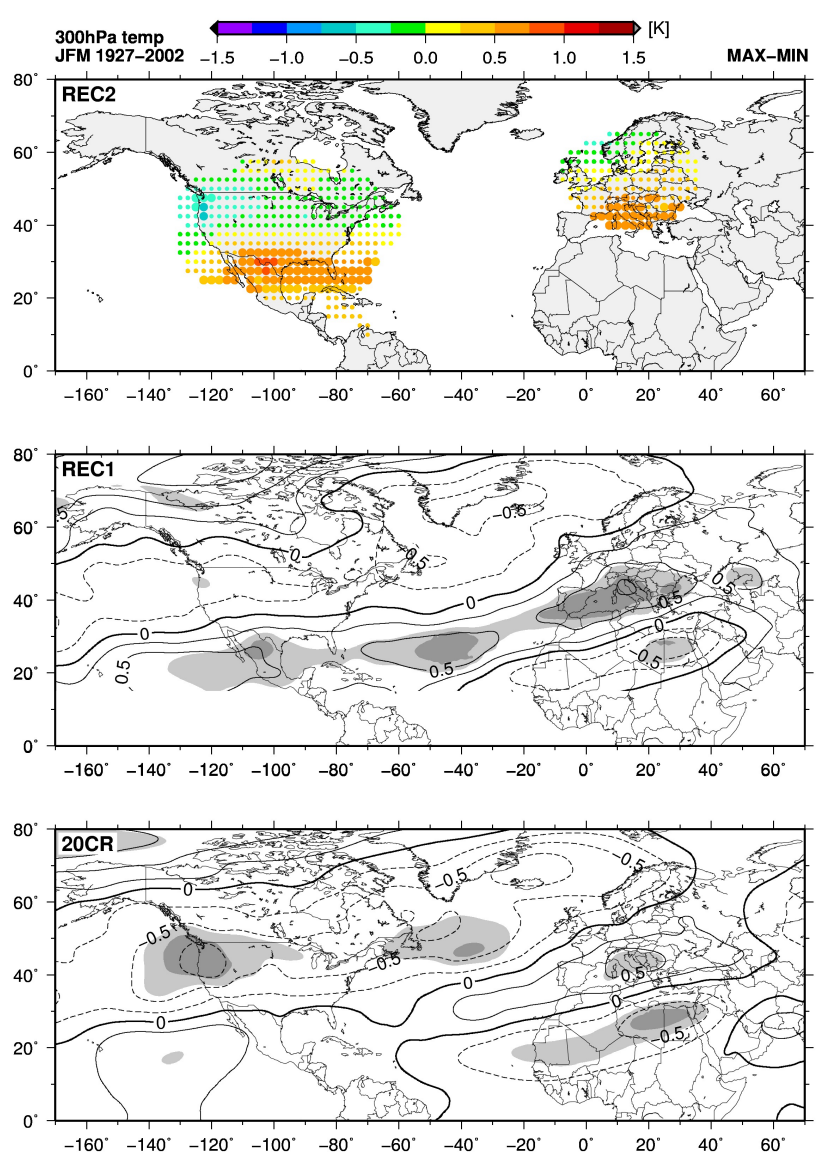

Fig. 10. Similar to Fig. 5, but showing temperature in K.

imprint over Europe, with up to $1.5 \mathrm{~K}$ of difference between maximum and minimum at $850 \mathrm{hPa}$, while the solar signal is not significant over North America (Fig. 11).

20CR results are much closer to the reconstructions for $850 \mathrm{hPa}$ temperatures compared to the $300 \mathrm{hPa}$ level, although they seem to underestimate the solar signal over eastern Europe (we recall that temperature on continents is entirely model-driven in 20CR).

\subsection{Vertical profiles}

Vertical cross sections are often used for the validation of climate models. In our case zonal averages are not very meaningful since our results cover only a fraction of the hemisphere. Nevertheless, it is worth looking at the vertical profile for grid points where the solar signal is particularly significant. This is shown in Fig. 12 for four grid points (REC2) over Europe where the solar influence reaches the maximum for the respective variables.

As expected, the signal is very similar for geopotential height and wind and shows a maximum in the upper troposphere. In the lower troposphere the signal is significant as well. The solar influence on temperature, on the other hand,
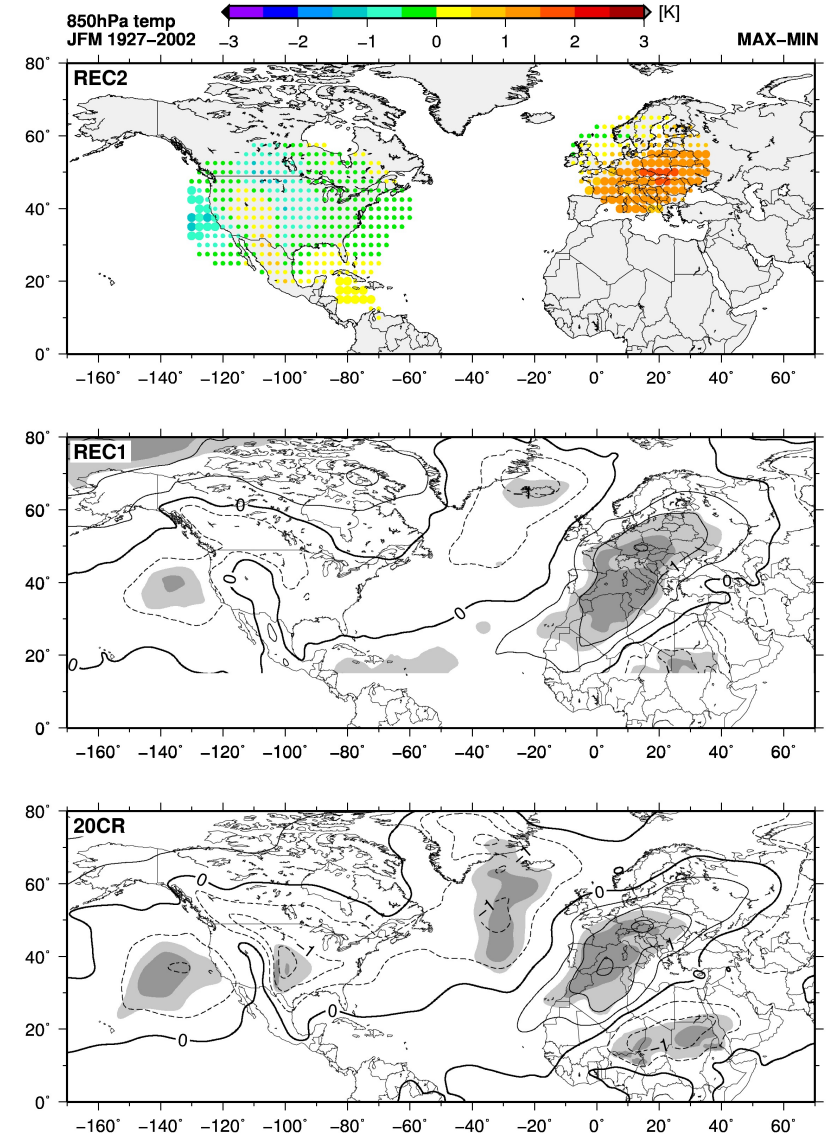

Fig. 11. Same as Fig. 10, but for $850 \mathrm{hPa}$.

decreases with height over eastern Europe, as also described in the previous section.

\subsection{Solar cycle 23}

The solar cycle 23 that ended in 2010 was distinguished by an unusually long and deep minimum (Russell et al., 2010), which lies outside the period analysed in this paper. It is interesting to look at the anomalies in the atmospheric circulation during the last minimum and to compare them with our results. Figure 13 shows the average anomalies for the winters (JFM) of 2005, 2006 and 2009 from 20CR (2007, 2008 and 2010 are not considered because they were influenced by strong ENSO episodes). Given the reduced number of years, the internal variability could in principle hide any solar influence even though the stronger source of variability (i.e. ENSO) was in large part removed. Nonetheless, the similarity to the results for 1927-2002 is striking for the EuroAtlantic sector (note that the signals have the opposite sign because we are now considering a minimum). 

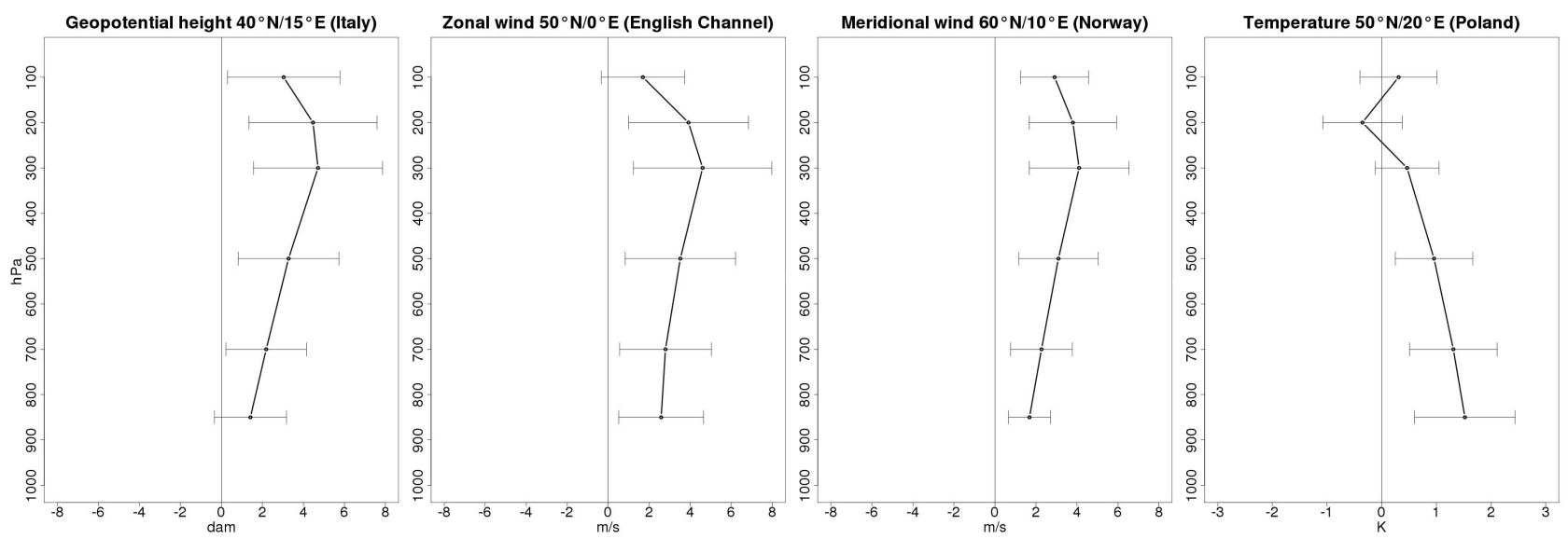

Fig. 12. Vertical profiles of the composites difference at four specific grid points (one grid point for each available variable). Error bars represent the $95 \%$ confidence intervals.
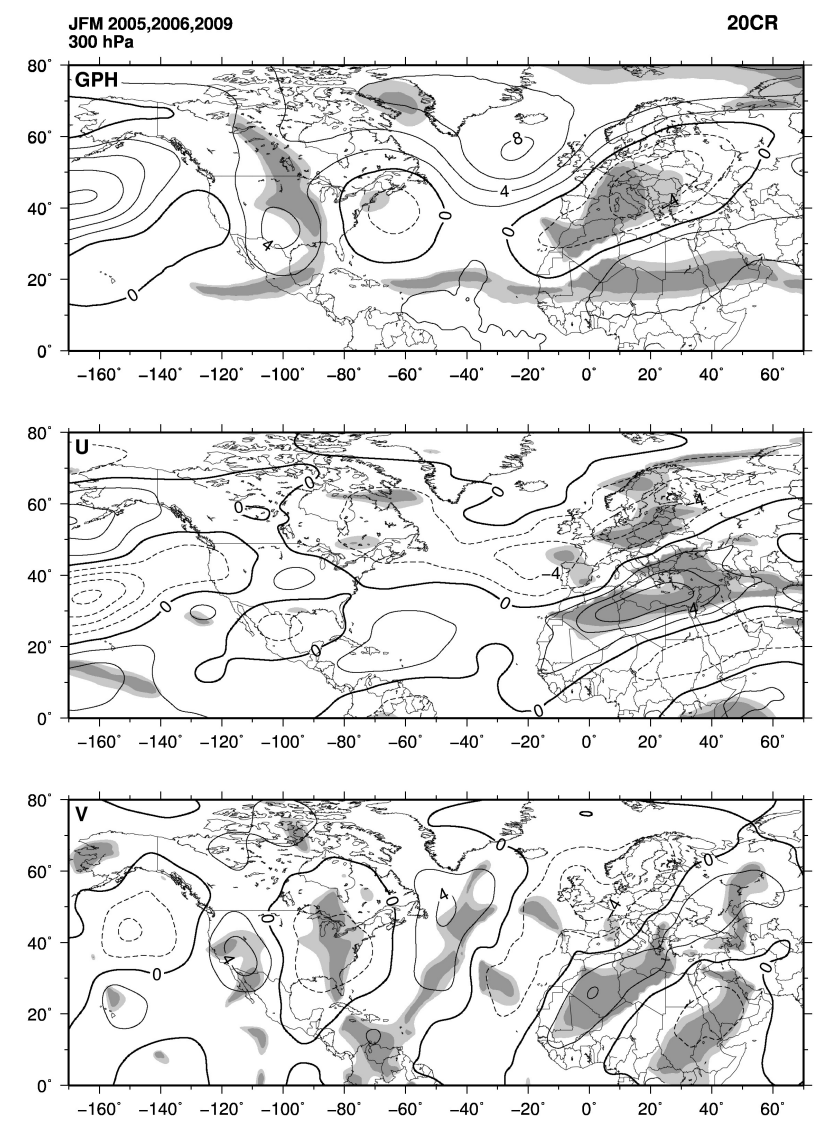

Fig. 13. Average anomalies (with respect to 1951-2000) in JFM during the years 2005, 2006 and 2009 in 20CR for geopotential height (top panel, in dam), zonal wind (middle panel, in $\mathrm{ms}^{-1}$ ) and meridional wind (bottom panel, in $\mathrm{m} \mathrm{s}^{-1}$ ). Shadings represent statistical significance like in the previous figures.

\section{Discussion and conclusions}

Our results described a physically consistent picture of the sunspot cycle influence on the tropospheric circulation in the Northern Hemisphere. An increased (decreased) horizontal thermal gradient between low and high latitudes in late winter during solar maxima (minima) is accompanied by stronger (weaker) westerlies, in particular over western Europe, and a smaller (larger) amplitude of the stationary planetary wave.

The length of the analysed period, covering seven sunspot cycles, allowed a more reliable statistical quantification of the solar signal than hitherto possible, since the analysis can be easily affected by the noise of the natural variability on short timescales. A Monte Carlo test confirmed that the solar influence over the analysed area is statistically significant for almost every level and every variable also when spatial autocorrelation is taken into account.

The Euro-Atlantic sector seems to be a region with a particularly strong solar influence on the troposphere. In fact, significant positive correlations between solar activity and surface temperature in Europe have been reported in several papers (e.g. Tung and Camp, 2008; Lean and Rind, 2008; Lockwood et al., 2010; Woollings et al., 2010), although long records tend to give very weak signals (van Oldenborgh et al., 2013). We found a weak but significant change in the mean late winter circulation over Europe, which results in detectable impacts on the near-surface climate. Figure 9 suggests that during solar minima more cold air is advected from the Arctic, thus resulting in a slightly increased probability of colder winters for large parts of the continent. Sirocko et al. (2012) recently reached the same conclusion after analysing $140 \mathrm{yr}$ in $20 \mathrm{CR}$, although their results are strongly dependent on their selection criteria for the solar minimum composite (van Oldenborgh et al., 2013), which includes only one winter for each solar cycle. This 
configuration could be related to an increased frequency of blockings over the eastern North Atlantic, which has been reported by Barriopedro et al. (2008). Some of the winters between 2005 and 2010, during a considerable long-lasting solar minimum, brought extreme cold spells over parts of Europe (Croci-Maspoli and Davies, 2009; Cattiaux et al., 2010; Guirguis et al., 2011), and it has already been suggested that the solar minimum may have played a role (Lockwood et al., 2010; Ineson et al., 2011). We showed that the average circulation pattern during those winters was the one expected in the condition of low solar activity.

We described a similar solar signal by analysing SLP reconstructions reaching back to the 18th century, giving us further confidence on its temporal stability, although the signal is weaker in the first half of the period.

Unlike some authors, we did not find a significant correlation between the solar activity and the NAO after analysing a $240 \mathrm{yr}$-long reconstruction of the NAO index, in agreement with van Oldenborgh et al. (2013). In such a long series, however, it was not possible to take into account the influence of the quasi-biennial oscillation (QBO), which can modulate the interaction between the solar cycle and the polar vortex (Labitzke et al., 2006; Haigh and Roscoe, 2009; Cnossen and $\mathrm{Lu}, 2011)$. Most of the earlier studies are based on shorter periods when the correlation between the NAO and the solar activity was indeed higher. In fact, after performing a runningcorrelation analysis, Thejll et al. (2003) pointed out that this correlation was highly variable over the last $130 \mathrm{yr}$; therefore very different results can arise by analysing only a few decades. Moreover, we found that the correlation between solar activity and SLP over Europe and the North Atlantic was much more variable for early winter than for late winter during the 20th century (not shown). A strong solar modulation of the NAO over the second half of the century, as described by Woollings et al. (2010) or by Ineson et al. (2011), might be a statistical artefact because even a small change in the length of the analysed period would have led to very different results.

It has been proposed that the solar variability also alters the spatial structure of the NAO (Kodera, 2003), a low solar activity being related to a more confined NAO signal. This complicates the analysis of solar influences on the NAO. We analysed another circulation index, namely the Eurasian index (representing the pressure see-saw between western and eastern Europe) and found a significant relationship with the $11 \mathrm{yr}$ cycle. This is an indication that this index is more linearly and steadily connected to the solar activity than the NAO index.

Our analysis suggests a possible weakening of the African branch of the sub-tropical jet during solar maxima. The reliability of upper-air data over northern Africa, however, is not very high at the moment and further investigations are needed.

These results can support the efforts of the scientific community to identify the physical mechanism behind the ob- served solar influence. One of the main candidates is the "top-down" mechanism (see Sect. 4.2 of Gray et al., 2010, and references therein), which originates from the larger variability in the UV band, its impact on the temperatures in the stratosphere by means of changes in the ozone's production rates, and the coupling between the stratosphere and the troposphere. Ineson et al. (2011) and Chiodo et al. (2012) recently simulated this process using an ocean-atmosphere climate model, producing results which are very similar to those we found in the SLP reconstruction, even though they used the standard DJF winter.

By comparing different data sets, we have shown that the 20CR is also suitable for this kind of analysis, bearing in mind some limitations. In this sense, a thorough investigation of some apparent inhomogeneities and their causes is necessary.

Future retrieval and digitisation of new historical upper-air data for the first part of the 20th century will further improve our understanding and estimation of the solar influence on the troposphere and will then facilitate the validation of the climate models, which remain fundamental for a full comprehension of the phenomenon.

\section{Supplementary material related to this article is

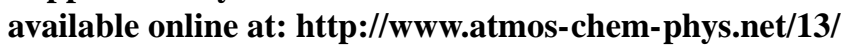 6275/2013/acp-13-6275-2013-supplement.pdf.}

Acknowledgements. This work was funded by the Swiss National Science Foundation through the Sinergia project FUPSOL (grant CRSI122-130642) and through NCCR Climate. We wish to thank ECMWF and the Royal Observatory of Belgium for providing ERA-40 data and the sunspot number, respectively. Support for the Twentieth Century Reanalysis Project dataset is provided by the U.S. Department of Energy, Office of Science Innovative and Novel Computational Impact on Theory and Experiment (DOE INCITE) program, and Office of Biological and Environmental Research (BER), and by the National Oceanic and Atmospheric Administration Climate Program Office. Jürg Luterbacher was supported by the EU/FP7 project ACQWA (\#212250), the German Science Fondation project PRIME 2 (Precipitation In past Millennia in Europe - extension back to Roman times) within the Priority Programme INTERDYNAMIK and the project Climate Change and Extreme Weather in Hesse - Analysis of observation data and ensemble projections for the 21 st century, funded by the Hessian Centre on Climate Change and Geology. We thank Geert Jan van Oldenborgh for fruitful discussions. Eugene Rozanov thanks COST Action ES1005TOSCA (http://www.tosca-cost.eu) for support.

Edited by: H. Wernli 


\section{References}

Allan, R. and Ansell, T.: A new globally complete monthly historical gridded mean sea level pressure dataset (HadSLP2): 18502004, J. Climate, 19, 5816-5842, doi:10.1175/JCLI3937.1, 2006.

Bal, S., Schimanke, S., Spangehl, T., and Cubasch, U.: On the robustness of the solar cycle signal in the Pacific region, Geophys. Res. Lett., 38, L14809, doi:10.1029/2011GL047964, 2011.

Barnston, A. G. and Livezey, R. E.: Classification, seasonality and persistence of low-frequency atmospheric circulation patterns, Mon. Weather Rev., 115, 1083-1126, 1987.

Barriopedro, D., García-Herrera, R., and Huth, R.: Solar modulation of Northern Hemisphere winter blocking, J. Geophys. Res., 113, D14118, doi:10.1029/2008JD009789, 2008.

Bengtsson, L., Hagemann, S., and Hodges, K. I.: Can climate trends be calculated from reanalysis data?, J. Geophys. Res., 109, D11111, doi:10.1029/2004JD004536, 2004.

Boberg, F. and Lundstedt, H.: Solar wind variations related to fluctuations of the North Atlantic Oscillation, Geophys. Res. Lett., 29, 1718, doi:10.1029/2002GL014903, 2002.

Boberg, F. and Lundstedt, H.: Solar wind electric field modulation of the NAO: A correlation analysis in the lower atmosphere, Geophys. Res. Lett., 30, 1825, doi:10.1029/2003GL017360, 2003.

Brönnimann, S., Ewen, T., Griesser, T., and Jenne, R.: Multidecadal signal of solar variability in the upper troposphere during the 20th century, Space Sci. Rev., 125, 305-317, doi:10.1007/s11214006-9065-2, 2007a.

Brönnimann, S., Xoplaki, E., Casty, C., Pauling, A., and Luterbacher, J.: ENSO influence on Europe during the last centuries, Clim. Dynam., 28, 181-197, doi:10.1007/s00382-006-0175-z, 2007b.

Brönnimann, S., Grant, A. N., Compo, G. P., Ewen, T., Griesser, T., Fischer, A. M., Schraner, M., and Stickler, A.: A multi-data set comparison of the vertical structure of temperature variability and change over the Arctic during the past 100 years, Clim. Dynam., 39, 1577-1598, doi:10.1007/s00382-012-1291-6, 2012a.

Brönnimann, S., Griesser, T., and Stickler, A.: A gridded monthly upper-air data set from 1918 to 1957, Clim. Dynam., 38, 475493, doi:10.1007/s00382-010-0940-x, 2012b.

Cattiaux, J., Vautard, R., Cassou, C., Yiou, P., Masson-Delmotte, V., and Codron, F.: Winter 2010 in Europe: A cold extreme in a warming climate, Geophyis. Res. Lett., 37, L20704, doi:10.1029/2010GL044613, 2010.

Chiodo, G., Calvo, N., Marsh, D. R., and Garcia-Herrera, R.: The 11 year solar cycle signal in transient simulations from the Whole Atmosphere Community Climate Model, J. Geophys. Res., 117, D06109, doi:10.1029/2011JD016393, 2012.

Cnossen, I. and Lu, H.: The vertical connection of the quasibiennial oscillation-modulated 11 year solar cycle signature in geopotential height and planetary waves during Northern Hemisphere early winter, J. Geophys. Res., 116, D13101, doi:10.1029/2010JD015427, 2011.

Compo, G. P., Whitaker, J. S., Sardeshmukh, P. D., Matsui, N., Allan, R. J., Yin, X., Gleason, B. E., Vose, R. S., Rutledge, G., Bessemoulin, P., Brönnimann, S., Brunet, M., Crouthamel, R. I., Grant, A. N., Groisman, P. Y., Jones, P. D., Kruk, M. C., Kruger, A. C., Marshall, G. J., Maugeri, M., Mok, H. Y., Nordli, Ø., Ross, T. F., Trigo, R. M., Wang, X. L., Woodruff, S. D., and Worley, S. J.: The Twentieth Century Reanalysis Project, Q. J. Roy. Meteo- rol. Soc., 137, 1-28, doi:10.1002/qj.776, 2011.

Croci-Maspoli, M. and Davies, H. C.: Key dynamical features of the 2005/2006 European winter, Mon. Weather Rev., 137, 664-678, doi:10.1175/2008MWR2533.1, 2009.

Crowley, T. J., Zielinski, G., Vinther, B., Udisti, R., Kreutz, K., Cole-Dai, J., and Castellano, E.: Volcanism and the little ice age, PAGES News, 16, 22-23, 2008.

Eddy, J. A.: The Maunder minimum, Science, 192, 1189-1202, 1976.

Enfield, D. B., Mestas-Nuñez, A. M., and Trimble, P. J.: The Atlantic Multidecadal Oscillation and its relation to rainfall and river flows in the continental U.S., Geophys. Res. Lett., 28, 2077-2080, doi:10.1029/2000GL012745, 2001.

Fischer, A. M., Shindell, D. T., Winter, B., Bourqui, M. S., Faluvegi, G., Rozanov, E., Schraner, M., and Brönnimann, S.: Stratospheric winter climate response to ENSO in three chemistry-climate models, Geophys. Res. Lett., 35, L13819, doi:10.1029/2008GL034289, 2008.

Frame, T. H. A. and Gray, L. J.: The 11-Yr Solar Cycle in ERA-40 Data: An Update to 2008, J. Climate, 23, 2213-2222, doi:10.1175/2009JCLI3150.1, 2010.

Garny, H., Bodeker, G. E., and Dameris, M.: Trends and variability in stratospheric mixing: 1979-2005, Atmos. Chem. Phys., 7, 5611-5624, doi:10.5194/acp-7-5611-2007, 2007.

Gleisner H., Thejill, P., Stendel, M., Kaas, E., and Machenhauer, B.: Solar signals in tropospheric re-analysis data: Comparing NCEP/NCAR and ERA40, J. Atmos. Sol.-Ter. Phy., 67, 785791, doi:10.1016/j.jastp.2005.02.001, 2005.

Graf H. F. and Zanchettin, D.: Central Pacific El Niño, the "subtropical bridge" and Eurasian Climate, J. Geophys. Res., 117, D01102, doi:10.1029/2011JD016493, 2012.

Gray, L. J., Beer, J., Geller, M., Haigh, J. D., Lockwood, M., Matthes, K., Cubasch, U., Fleitmann, D., Harrison, G., Hood, L., Luterbacher, J., Meehl, G. A., Shindell, D., van Geel, B., and White, W.: Solar influences on climate, Rev. Geophys., 48, RG4001, doi:10.1029/2009RG000282, 2010.

Griesser, T., Brönnimann, S., Grant, A., Ewen, T., Stickler, A., and Comeaux, J.: Reconstruction of global monthly upper-level temperature and geopotential height fields back to 1880 , J. Climate, 23, 5590-5609, doi:10.1175/2010JCLI3056.1, 2010.

Guirguis, K., Gershunov, A., Schwartz, R., and Bennett, S.: Recent warm and cold daily winter temperature extremes in the Northern Hemisphere, Geophys. Res. Lett., 38, L17701, doi:10.1029/2011GL048762, 2011.

Haigh, J. D.: The effects of solar variability on the Earth's climate, Phil. Trans. R. Soc. Lond. A., 361, 95-111, doi:10.1098/rsta.2002.1111, 2003.

Haigh, J. D. and Roscoe, H. K.: The final warming date of the Antarctic polar vortex and influences on its interannual variability, J. Climate, 22, 5809-5819, doi:10.1175/2009JCLI2865.1, 2009.

Haigh, J. D., Winning, A. R., Toumi, R., and Harder, J. W.: An influence of solar spectral variations on radiative forcing of climate, Nature, 467, 696-699, doi:10.1038/nature09426, 2010.

Hansen, J., Ruedy, R., Glascoe, J., and Sato, M.: GISS analysis of surface temperature change, J. Geophys. Res., 104, 3099731022, 1999.

Harder, J. W., Fontenla, J. M., Pilewskie, P., Richard, E. C., and Woods, T. N.: Trends in solar spectral irradiance variability 
in the visible and infrared, Geophys. Res. Lett., 36, L07801, doi:10.1029/2008GL036797, 2009.

Hebert III, L., Tinsley, B. A., and Zhou, L.: Global electric circuit modulation of winter cyclone vorticity in the northern high latitudes, Adv. Space Res., 50, 806-818, doi:10.1016/j.asr.2012.03.002, 2012.

Ineson, S., Scaife, A. A., Knight, J. R., Manners, J. C., Dunstone, N. J., Gray, L. J., and Haigh, J. D.: Solar forcing of winter climate variability in the northern hemisphere, Nat. Geosci., 4, 753-757, doi:10.1038/NGEO1282, 2011.

Kalnay, E., Kanamitsu, M., Kistler, R., Collins, W., Deaven, D., Gandin, L., Iredell, M., Saha, S., White, G., Woollen, J., Zhu, Y., Chelliah, M., Ebisuzaki, W., Higgins, W., Janowiak, J., Mo, K., Ropelewski, C., Wang, J., Leetmaa, A., Reynolds, R., Jenne, R., and Joseph, D.: The NCEP/NCAR 40-year re-analysis project, Bull. Amer. Meteor. Soc., 77, 437-471, doi:10.1175/15200477(1996)077<0437:TNYRP>2.0.CO;2, 1996.

Kazil, J., Lovejoy, E. R., Barth, M. C., and O'Brien, K.: Aerosol nucleation over oceans and the role of galactic cosmic rays, Atmos. Chem. Phys., 6, 4905-4924, doi:10.5194/acp-6-4905-2006, 2006.

Kinter, J. L., Fennessy, M. J., Krishnamurthy, V., and Marx, L.: An evaluation of the apparent interdecadal shift in the tropical divergent circulation in the NCEP-NCAR Reanalysis, J. Climate, 17, 349-361, doi:10.1175/15200442(2004)017<0349:AEOTAI > 2.0.CO;2, 2004.

Kistler, R., Kalnay, E., Collins, W., Saha, S., White, G., Woollen, J., Chelliah, M., Ebisuzaki, W., Kanamitsu, M., Kousky, V., van den Dool, H., Jenne, R., and Fiorino, M.: The NCEP-NCAR 50-Year Reanalysis: Monthly Means CD-ROM and Documentation, B. Am. Meteor. Soc., 82, 247-267, doi:10.1175/15200477(2001)082<0247:TNNYRM>2.3.CO;2, 2001.

Kodera, K.: Solar influence on the spatial structure of the NAO during the winter 1900-1999, Geophys. Res. Lett., 30, 1175, doi:10.1029/2002GL016584, 2003.

Küttel, M., Luterbacher, J., and Wanner, H.: Multidecadal changes in winter circulation-climate relationship in Europe: frequency variations, within-type modifications, and long-term trends, Clim. Dyn., 36, 957-972, doi:10.1007/s00382-009-0737-y, 2011.

Labitzke, K., Kunze, M., and Brönnimann, S.: Sunspots, the QBO and the stratosphere in the north polar region - 20 years later, Meteorol. Z., 15, 355-363, doi:10.1127/0941-2948/2006/0136, 2006.

Lean, J. L. and Rind, D. H.: How natural and anthropogenic influences alter global and regional surface temperatures: 1889 to 2006, Geophys. Res. Lett., 35, L1870, doi:10.1029/2008GL034864, 2008.

Livezey, R. E. and Chen, W. Y.: Statistical field significance and its determination by Monte Carlo techniques, Mon. Weather Rev., 111, 46-59, 1983.

Lockwood, M.: Solar influence on global and regional climates, Surv. Geophys., 33, 503-534, doi:10.1007/s10712-012-9181-3, 2012.

Lockwood, M., Harrison, R. G., Woollings, T., and Solanki, S.: Are cold winters in Europe associated with low solar activity?, Environ. Res. Lett., 5, 024001, doi:10.1088/1748-9326/5/2/024001, 2010 .
Luterbacher, J., Schmutz, C., Gyalistras, D., Xoplaki, E., and Wanner, H.: Reconstruction of monthly NAO and EU indices back to AD 1675, Geophys. Res. Lett., 26, 2745-2748, doi:10.1029/1999GL900576, 1999.

Luterbacher, J., Xoplaki, E., Dietrich, D., Jones, P. D., Davies, T. D., Portis, D., Gonzalez-Rouco, J. F., von Storch, H., Gyalistras, D., Casty, C., and Wanner, H.: Extending North Atlantic oscillation reconstructions back to 1500, Atmos. Sci. Lett., 2, 114-124, doi:10.1006/asle.2002.0047, 2001.

Luterbacher, J., Xoplaki, E., Dietrich, D., Rickli, R., Jacobeit, J., Beck, C., Gyalistras, D., Schmutz, C., and Wanner, H.: Reconstruction of sea level pressure fields over the eastern North Atlantic and Europe back to 1500, Clim. Dynam., 18, 545-561, doi:10.1007/S00382-001-0196-6, 2002.

Martin-Puertas, C., Matthes, K., Brauer, A., Muscheler, R., Hansen, F., Petrick, C., Aldahan, A., Possnert, G., and van Geel, B.: Regional atmospheric circulation shifts induced by a grand solar minimum, Nature Geosci., 5, 397-401, doi:10.1038/ngeo1460, 2012.

Meehl, G. A., Arblaster, J. M., Branstator, G., and van Loon, H.: A coupled air-sea response mechanism to solar forcing in the Pacific region, J. Clim., 21, 2883-2897, doi:10.1175/2007JCLI1776.1, 2008.

Meehl, G. A., Arblaster, J. M., Matthes, K., Sassi, F., and van Loon, H.: Amplifying the Pacific climate system response to a small 11-year solar cycle forcing, Science, 325, 1114-1118, doi:10.1126/science.1172872, 2009.

Moron, V. and Plaut, G.: The impact of El Niño-southern oscillation upon weather regimes over Europe and the North Atlantic during boreal winter. Int. J. Climatol., 23, 363-379, doi:10.1002/joc.890, 2003.

Peixoto, J. P. and Oort, A. H.: Observed mean state of the atmosphere, in: Physics of Climate, Springer-Verlag, New York, USA, 1992.

Rayner, N. A., Parker, D. E., Horton, E. B., Folland, C. K., Alexander, L. V., Rowell, D. P., Kent, E. C., and Kaplan, A.: Global analyses of sea surface temperature, sea ice, and night marine air temperature since the late nineteenth century, J. Geophys. Res., 108, 4407, doi:10.1029/2002JD002670, 2003.

Rayner, N. A., Brohan, P., Parker, D. E., Folland, C. K., Kennedy, J. J., Vanicek, M., Ansell, T. J., and Tett, S. F. B.: Improved analyses of changes and uncertainties in sea surface temperature measured in situ since the mid-nineteenth century: The HadSST2 dataset, J. Climate, 19, 446-469, doi:10.1175/JCLI3637.1, 2006.

Rex, D. F.: Blocking action in the middle troposphere and its effect upon regional climate. Part II: The climatology of blocking action, Tellus, 2, 275-301, doi:10.1111/j.21533490.1950.tb00339.x, 1950.

Rodwell, M. J.: On the predictability of North Atlantic climate, in: The North Atlantic Oscillation: climatic significance and environmental impact, Geophys. Monogr. Ser., 134, edited by: Hurrell, J. W., Kushnir, Y., Ottersen, G., and Visbeck, M., Washington, DC, 173-192, doi:10.1029/134GM08, 2003.

Roy, I. and Haigh, J. D.: Solar cycle signals in sea level pressure and sea surface temperature, Atmos. Chem. Phys., 10, 3147-3153, doi:10.5194/acp-10-3147-2010, 2010.

Roy, I. and Haigh, J. D.: The influence of solar variability and the quasi-biennial oscillation on lower atmospheric temperatures and sea level pressure, Atmos. Chem. Phys., 11, 11679-11687, 
doi:10.5194/acp-11-11679-2011, 2011.

Russell, C. T., Luhmann, J. G., and Jian, L. K.: How unprecedented a solar minimum?, Rev. Geophys., 48, RG2004, doi:10.1029/2009RG000316, 2010.

Schmutz, C. and Wanner, H.: Low frequency variability of atmospheric circulation over Europe between 1785 and 1994, Erdkunde, 52, 81-94, 1998.

Schrijver, C. J., Livingston, W. C., Woods, T. N., and Mewaldt, R.A.: The minimal solar activity in 2008-2009 and its implications for long-term climate modelling, Geophys. Res. Lett., 38, L06701, doi:10.1029/2011GL046658, 2011.

Shapiro, A. I., Schmutz, W., Rozanov, E., Schoell, M., Haberreiter, M., Shapiro, A. V., and Nyeki, S.: A new approach to the long-term reconstruction of the solar irradiance leads to large historical solar forcing, Astron. Astrophys., 529, A67, doi:10.1051/0004-6361/201016173, 2011.

Shindell, D. T., Rind, D., Balachandran, N. K., Lean, J., and Lonergan, P.: Solar cycle variability, ozone, and climate, Science, 284, 305-308, doi:10.1126/science.284.5412.305, 1999.

Shindell, D. T., Schmidt, G. A., Mann, M. E., Rind, D., and Waple, A.: Solar forcing of regional climate change during the Maunder Minimum, Science, 294, 2149-2152, doi:10.1126/science.1064363, 2001.

Sirocko, F., Brunck, H., and Pfahl, S.: Solar influence on winter severity in central Europe, Geophys. Res. Lett., 39, L16704, doi:10.1029/2012GL052412, 2012.

Stickler, A., Grant, A. N., Ewen, T., Ross, T. F., Vose, R. S., Comeaux, J., Bessemoulin, P., Jylhä, K., Adam, W. K., Jeannet, P., Nagurny, A., Sterin, A. M., Allan, R., Compo, G. P., Griesser, T., and Brönnimann, S.: The Comprehensive Historical Upper-Air Network, B. Am. Meteorol. Soc., 91, 741-751, doi:10.1175/2009BAMS2852.1, 2010.

Thejll, P., Christiansen, B., and Gleisner, H.: On correlations between the North Atlantic Oscillation, geopotential heights, and geomagnetic activity, Geophys. Res. Lett., 30, 1347, doi:10.1029/2002GL016598, 2003.

Thompson, D. W. J., Kennedy, J. J, Wallace, J. M., and Jones, P. D.: A large discontinuity in the mid-twentieth century in observed global-mean surface temperature, Nature 453, 646-649, doi:10.1038/nature06982, 2008.

Tinsley, B. A.: Influence of solar wind on the global electric circuit, and inferred effects on cloud microphysics, temperature, and dynamics in the troposphere, Space Sci. Rev., 94, 231-258, doi:10.1023/A:1026775408875, 2000.

Tinsley, B. A.: A working hypothesis for connections between electrically-induced changes in cloud microphysics and storm vorticity, with possible effects on circulation, Adv. Space Res., 50, 791-805, doi:10.1016/j.asr.2012.04.008, 2012.

Tinsley, B. A. and Yu, F.: Atmospheric ionization and clouds as links between solar activity and climate, in: Solar variability and its effects on climate, Geophysical Monograph, vol. 141, AGU Press, Washington, DC, 321-339, 2004.
Tinsley, B. A, Brown G. M., and Scherrer, P. H.: Solar variability influences on weather and climate: possible connections through cosmic ray-fluxes and storm intensification, J. Geophys. Res., 94, 14783-14792, doi:10.1029/JD094iD12p14783, 1989.

Tung, K. K. and Camp, C. D.: Solar cycle warming at the Earth's surface in NCEP and ERA-40 data: A linear discriminant analysis, J. Geophys. Res., 113, D05114, doi:10.1029/2007JD009164, 2008.

Uppala, S. M., Kållberg, P. W., Simmons, A. J., Andrae, U., da Costa Bechtold, V., Fiorino, M., Gibson, J. K., Haseler, J., Hernandez, A., Kelly, G. A., Li, X., Onogi, K., Saarinen, S., Sokka, N., Allan, R. P., Andersson, E., Arpe, K., Balmaseda, M. A., Beljaars, A. C. M., van de Berg, L., Bidlot, J., Bormann, N., Caires, S., Chevallier, F., Dethof, A., Dragosavac, M., Fisher, M., Fuentes, M., Hagemann, S., Hólm, E., Hoskins, B. J., Isaksen, L., Janssen, P. A. E. M., Jenne, R., McNally, A. P., Mahfouf, J.-F., Morcrette, J.-J., Rayner, N. A., Saunders, R. W., Simon, P., Sterl, A., Trenberth, K. E., Untch, A., Vasiljevic, D., Viterbo, P., and Woollen, J.: The ERA-40 re-analysis, Q. J. Roy. Meteorol. Soc., 131, 2961-3012, doi:10.1256/qj.04.176, 2005.

van Oldenborgh, G. J., de Laat, A. T. J., Luterbacher, J., Ingram, W. J., and Osborn, T. J.: Claim of solar influence is on thin ice: are 11-year cycle solar minima associated with severe winters in Europe?, Environ. Res. Lett., 8, 024014, doi:10.1088/17489326/8/2/024014, 2013.

van Loon, H., Meehl, G. A., and Shea, D. J.: Coupled air-sea response to solar forcing in the Pacific region during northern winter, J. Geophys. Res., 112, D02108, doi:10.1029/2006JD007378, 2007.

Wibig, J.: Precipitation in Europe in relation to circulation patterns at the $500 \mathrm{hPa}$ level, Int. J. Climatol., 19, 253269, doi:10.1002/(SICI)1097-0088(19990315)19:3<253::AIDJOC366>3.0.CO;2-0, 1999.

Woollings, T., Lockwood, M., Masato, G., Bell, C., and Gray, L.: Enhanced signature of solar variability in Eurasian winter climate, Geophys. Res. Lett., 37, L20805, doi:10.1029/2010GL044601, 2010.

Xoplaki, E., Gonzalez-Rouco, J. F., Luterbacher, J., and Wanner, H.: Wet season Mediterranean precipitation variability: influence of large-scale dynamics and trends, Clim. Dyn., 23, 63-78, doi:10.1007/s00382-004-0422-0, 2004.

Zanchettin, D., Bothe, O., Graf, H-F., Lorenz, S. J., Luterbacher, J., Timmreck, C., and Jungclaus, J. H.: Background conditions influence the decadal climate response to strong volcanic eruptions, J. Geophys. Res., 118, doi:10.1002/jgrd.50229, 2013a.

Zanchettin, D., Timmreck, C., Bothe, O., Lorenz, S. J., Hegerl, G., Graf, H-F., Luterbacher, J., and Jungclaus, J. H.: Delayed winter warming: a robust decadal response to strong tropical volcanic eruptions?, Geophys. Res. Lett., 40, 204-209, doi:10.1029/2012GL054403, 2013b. 